\title{
The relationship between sitting height, sitting height to height ratio with blood pressure among Polokwane private school children aged 6-13 years
}

\author{
Nthai E. Ramoshaba*, Kotsedi D. Monyeki, Joyce Mpya and Mafolwa S. Monyeki
}

\begin{abstract}
Background: It is notable that sitting height (SH) correlates with blood pressure (BP) in children and adolescents of developed countries. However, little is known about the relationships between SH and SH to height ratio $(\mathrm{SH} / \mathrm{H})$ with $\mathrm{BP}$ in South African children from middle and upper socio-economic groups. The purpose of this study was to compare $\mathrm{SH}$ and $\mathrm{SH} / \mathrm{H}$ of private school attending children in the Polokwane area with National Health and Nutrition Examination Survey III (NHANES III) reference population and to determine the relationship between $\mathrm{SH}, \mathrm{SH} / \mathrm{H}$ with $\mathrm{BP}$ among private school attending children.

Methods: A total of 1665 children ( 846 boys and 819 girls) aged between 6 and 13 years attending three private schools in Polokwane, underwent anthropometric and BP measurements using standard procedures. Linear regression was used to determine the relationship between height, $\mathrm{SH}, \mathrm{SH} / \mathrm{H}$ with BP among these children.

Results: Polokwane private school attending boys from age 7 to 13 years displayed a lower mean SH compared to the NHANES III whereas NHANHES III girls from age 10 to 13 years had a higher mean SH compared to those in private school. In the simple regression analysis, SH was positively associated with SBP $(\beta=1.318 ; 95 \% \mathrm{Cl}=1.217-1$. $418)$ and $\mathrm{DBP}(\beta=0.641 ; 95 \% \mathrm{Cl}=0.555-0.727)$. The findings remains statistically significant only for SH with both $\operatorname{SBP}(\beta=1.025 ; 95 \% \mathrm{Cl}=0.844-1.201)$ and $\mathrm{DBP}(\beta=0.585 ; 95 \% \mathrm{Cl} 0.434-0.736)$ after adjusting for age, gender and BMI among these children.
\end{abstract}

Conclusion: In South African children, SH and SH/H were lower compared to the NHANES III children. There was a significant positive association between DBP and SBP together with the components of height among Polokwane private school children.

Keywords: Sitting height, Blood pressure, Private school, Children, South Africa

\section{Background}

High blood pressure (BP) is a major public health obstacle that leads to morbidity and mortality in both developed and developing countries [1-3]. Existing literature indicates that sustained high $\mathrm{BP}$ in children is associated with the risk factors of cardiovascular diseases (CVD) in sub-Saharan African adults [4]. Moreover, child growth proportion has shown close links with the development of CVD risk factors. Most

\footnotetext{
* Correspondence: pro.elfas@gmail.com

Department of Physiology \& Environmental Health, University of Limpopo, Polokwane, South Africa
}

studies reported that height can be used as a predictor Height can be divided into three components, sitting height $(\mathrm{SH})$, leg length and $\mathrm{SH}$ to height ratio $(\mathrm{SH} / \mathrm{H})$ which are pivotal in the assessment of growth proportion. $\mathrm{SH}$ not $\mathrm{SH} / \mathrm{H}$ was reported to be associated with BP in Brazilian children [8]. Furthermore, Dong et al. [9] study exhibited that SH was associated with BP in Chinese children and adolescents. Recent findings showed that significant relationships between $\mathrm{SH}$ with both systolic BP (SBP) and diastolic BP (DBP) in rural South African children exists [10].

The association between $\mathrm{SH}$ and $\mathrm{SH} / \mathrm{H}$ with $\mathrm{BP}$ in children from middle and upper socio-economic status 
with the prevalence of hypertension ranged from 0.9$12.9 \%$ and overweight ranged from 0 to $22.6 \%$ is scant [11]. To reiterate, the purpose of the study was first, to compare $\mathrm{SH}$ and $\mathrm{SH} / \mathrm{H}$ of Polokwane private school attending children with the National Health and Nutrition Examination Survey III (NHANES III) reference population. Finally, it was to determine the relationship between $\mathrm{SH}$ and $\mathrm{SH} / \mathrm{H}$ with $\mathrm{BP}$ among Polokwane private school attending children.

\section{Methods}

\section{Study population and ethical approval}

A total of 1665 children (846 boys and 819 girls), aged 6 to 13 years, attending three private schools in Polokwane, a city in the Limpopo Province of South Africa, participated in the study. The majority of participants were black children $(99.77 \%)$, while $0.2 \%$ were white and coloureds made up the $0.01 \%$ with Indians at $0.02 \%$ were in a minority and as a result were excluded in the analysis. Generally, children attending private schools in South Africa fall within the middle and upper socio-economic groups of the population. All the children who were present at the schools during the days of the survey participated in the study. The Ethics Committee of the University of Limpopo granted ethical approval prior to the study. Written informed consent was obtained from parents or guardians.

\section{Anthropometric measurements}

The children were anthropometrically measured using the International Society for the Advancement of Kinanthropometry (ISAK) [12]. A Martin anthropometer was used to measure height to the nearest $0.1 \mathrm{~cm}$. The $\mathrm{SH}$ was measured by bringing the horizontal bar of Martin anthropometer to the most superior midline of the head while the child was sitting in the erect position on a flat stool or box. Weight was measured on an electronic scale to the nearest $0.1 \mathrm{~kg}$. Body mass index (BMI) was calculated as weight $(\mathrm{kg}) /(\text { height }(\mathrm{cm}))^{2}$.

\section{Blood pressure}

Using an electronic Micronta monitoring kit (Omron), at least three $\mathrm{BP}$ readings of SBP and DBP were taken at 5 min intervals after the child had been seated for $5 \mathrm{~min}$ or longer $[13,14]$. The bladder device contains an electronic infrasonic transducer that monitors the BP and pulse rate, displaying those concurrently on the screen. This versatile instrument has been designed for research and clinical purposes. In a pilot study, conducted before the survey, a high correlation $(r=0.93)$ was found between the readings taken with the automated device and those taken with a conventional Sphygmomanometer.

\section{Statistical analysis}

Descriptive statistics were performed for height, $\mathrm{SH}, \mathrm{SH} /$ $\mathrm{H}$, and $\mathrm{BP}$ with the Polokwane private school children aged 6-13 years. Student's t-test was utilised to test the significant difference between the genders. $\mathrm{SH}$ and $\mathrm{SH} /$ $\mathrm{H}$ of private school children were compared with NHANES III reference population [15]. The linear regression models were used to analyse the relationship between BP (SBP: Systolic Blood Pressure and DBP: Diastolic Blood Pressure) and components of height (height, $\mathrm{SH}$ and $\mathrm{SH} / \mathrm{H}$ ) and were unadjusted and adjusted regarding to age and gender. All statistical analyses were performed using the Statistical Package for the Social Sciences (SPSS) version 23. The statistical significance was set at $P<0.05$.

\section{Results}

Table 1 reflects descriptive statistics for height, $\mathrm{SH}$ and $\mathrm{SH} / \mathrm{H}$ among Polokwane private school boys and girls

Table 1 Descriptive statistics for height, sitting height and sitting height/height ratio of Polokwane private schools children, age 6-13 years

\begin{tabular}{|c|c|c|c|c|c|c|c|c|}
\hline \multirow{3}{*}{ Age (years) } & \multicolumn{2}{|c|}{ Sample size } & \multicolumn{2}{|l|}{ Height (cm) } & \multicolumn{2}{|l|}{$\mathrm{SH}(\mathrm{cm})$} & \multicolumn{2}{|l|}{$\mathrm{SH} / \mathrm{H}(\%)$} \\
\hline & Boys & Girls & Boys & Girls & Boys & Girls & Boys & Girls \\
\hline & & & $M(S D)$ & $M(S D)$ & $M(S D)$ & $M(S D)$ & $M(S D)$ & $M(S D)$ \\
\hline 6 & 74 & 94 & $122.8(5.4)$ & $121.6(5.8)$ & $65.7(2.9)$ & $65.1(2.7)$ & $53.5(1.2)$ & $53.6(1.7)$ \\
\hline 7 & 118 & 122 & $126.8(6.0)$ & $126.2(7.5)$ & $67.0^{*}(3.2)$ & $66.2^{*}(2.8)$ & $52.9(1.8)$ & 52.5 \\
\hline 8 & 116 & 117 & $131.5(6.9)$ & $131.7(5.2)$ & $68.6(3.0)$ & $68.6(2.5)$ & $52.3(1.9)$ & $52.1(1.3)$ \\
\hline 9 & 106 & 106 & $136.1(6.9)$ & $137.5(6.6)$ & $70.5(3.2)$ & $71.2(3.4)$ & $51.8(1.6)$ & $51.8(1.5)$ \\
\hline 10 & 117 & 104 & $142.1^{*}(6.0)$ & $144.0^{*}(6.8)$ & $72.8(2.8)$ & $73.6(5.3)$ & $51.3(1.4)$ & $51.1(1.8)$ \\
\hline 11 & 140 & 140 & $146.6^{*}(6.6)$ & $150.0^{*}(7.7)$ & $74.4^{*}(3.1)$ & $76.5^{*}(3.7)$ & $50.8(1.7)$ & $51.0(1.3)$ \\
\hline 12 & 104 & 93 & $151.2^{*}(8.2)$ & $155.7^{*}(7.8)$ & $76.7^{*}(3.4)$ & $79.0^{*}(3.5)$ & $50.7(1.3)$ & $50.8(1.5)$ \\
\hline 13 & 71 & 43 & $156.3^{*}(7.3)$ & $160.0^{*}(7.0)$ & $78.9^{*}(3.6)$ & $81.3^{*}(2.8)$ & $50.5(1.7)$ & $50.9(1.7)$ \\
\hline Total & 846 & 819 & $139.2^{*}(12.3)$ & $139.4^{*}(13.9)$ & $71.8^{*}(5.2)$ & $72.0^{*}(6.0)$ & $51.7(0.12)$ & $51.8(0.12)$ \\
\hline
\end{tabular}

${ }^{*}=P<0.05 ; M$ mean, $S D$ standard deviation, $S H$ sitting height, $S H / H$ sitting height/height ratio 


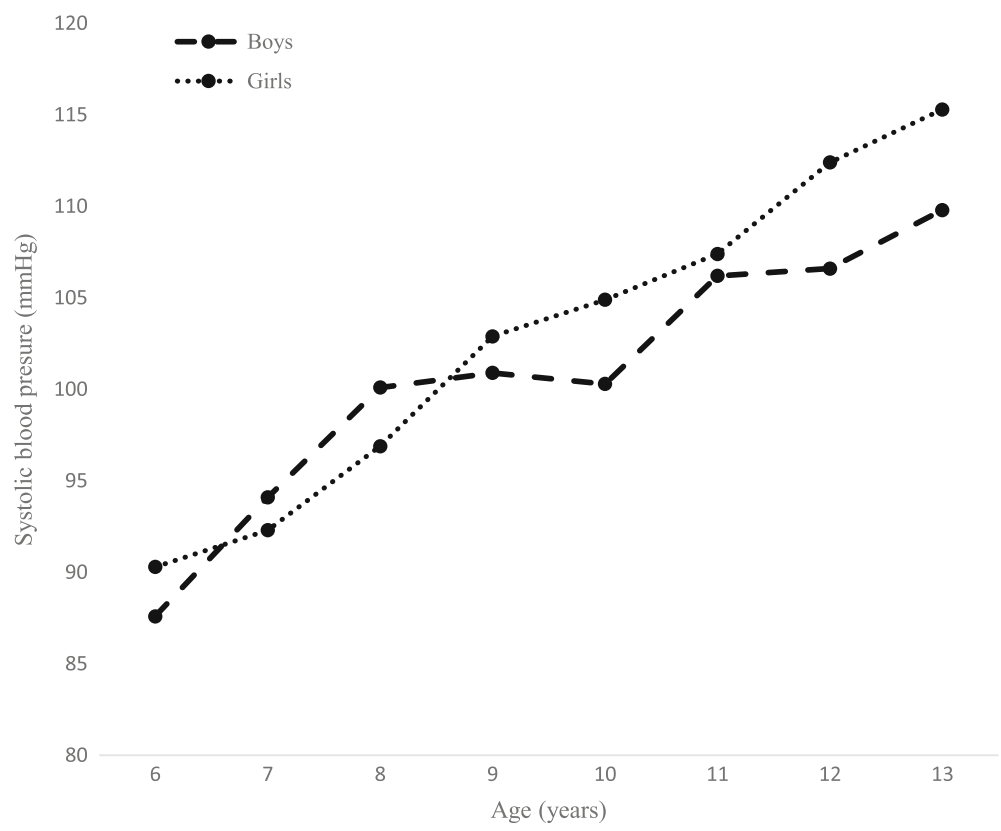

Fig. 1 The comparison of systolic blood pressure by age among Polokwane private schools children

aged 6-13 years. At age 11-13 years, girls mean $\mathrm{SH}$ $(76.5 \mathrm{~cm}-81.3 \mathrm{~cm})$ were significantly $(\mathrm{P}<0.05)$ higher than boys mean $\mathrm{SH}(74.4 \mathrm{~cm}-78.9 \mathrm{~cm})$. Overall, girls' mean $\mathrm{SH}(72.0 \mathrm{~cm})$ was significantly higher than boys mean SH $(71.8 \mathrm{~cm})$. Both SBP and DBP increased proportionally with age for both genders (Figs. 1 and 2).

Figs. 3 and 4 showed the comparison between $\mathrm{SH}, \mathrm{SH} /$ $\mathrm{H}$ mean values between Polokwane private school and NHANES III children aged 6-13 years. Polokwane private school boys showed a lower mean $\mathrm{SH}$ compared to NHANES III boys from age 7 to 13 years whereas NHANHES III girls had a higher mean SH compared to private school girls from age 10 to 13 years. Figure 4 exhibits an inverse decrease in $\mathrm{SH} / \mathrm{H}$ with age, where mean $\mathrm{SH} / \mathrm{H}$ among Polokwane private school children were low compared to the NHANES III children for both genders.

Table 2 showed linear regression for the association between height, $\mathrm{SH}, \mathrm{SH} / \mathrm{H}$ with $\mathrm{BP}$ in Polokwane private

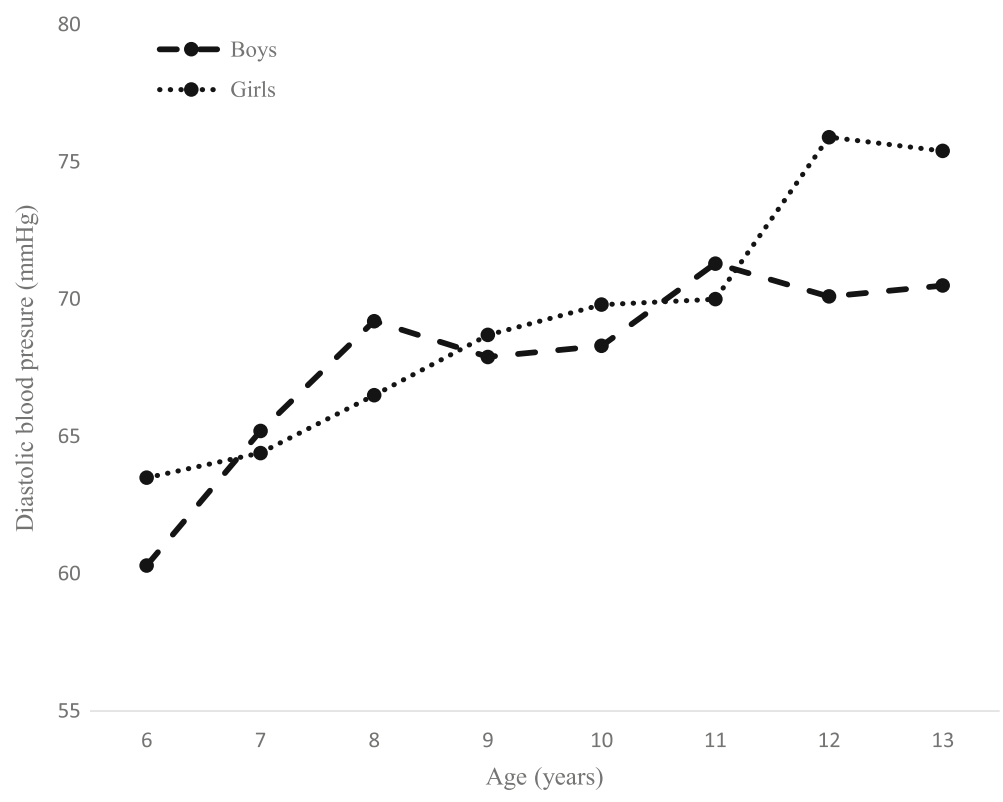

Fig. 2 The comparison of diastolic blood pressure by age among Polokwane private school children 


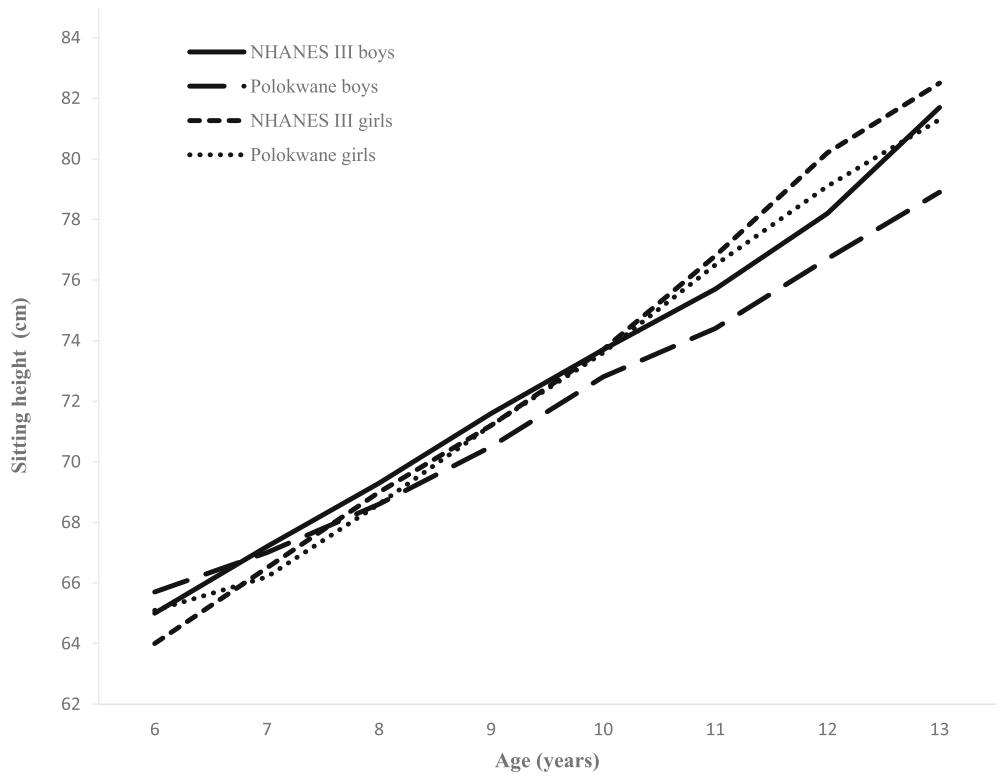

Fig. 3 The comparison of mean sitting height between Polokwane and NHANES III children

school attending children, unadjusted and adjusted for age, gender and BMI. There was a significant association $(P<$ $0.001)$ between SH with SBP $(\beta=1.318$; $95 \% \mathrm{CI}=1.217$ $1.418)$ and $\mathrm{DBP}(\beta=0.641 ; 95 \% \mathrm{Cl}=0.555-0.727)$ for unadjusted. After adjusted for age, gender and BMI, $\mathrm{SH}$ was significantly associated with both SBP $(\beta=0.691 ; 95 \%$ $\mathrm{Cl}=0.509-0.872)$ and DBP $(\beta=0.304 ; 95 \% \mathrm{Cl} 0.148-0.460)$ among these children. Furthermore, $\mathrm{SH} / \mathrm{H}$ was associated $(P<0.05)$ with SBP and DBP for unadjusted only.

\section{Discussion}

This cross-sectional study described the relationship between $\mathrm{SH}, \mathrm{SH} / \mathrm{H}$ and $\mathrm{BP}$ among children aged between
6 to 13 years attending private school in Polokwane. SH and $\mathrm{SH} / \mathrm{H}$ was significantly associated with $\mathrm{SBP}$ and $\mathrm{DBP}$ in the unadjusted analysis. However, after being adjusted for age, gender and BMI, only SH remained associated with both SBP and DBP.

An increase in age of children increases with the mean $\mathrm{SH}$ and decreases with the mean $\mathrm{SH} / \mathrm{H}$ in the current study. This is in agreement with others studies reported that height increases with age and is mainly due to an increase in lower limb rather than in upper limb or $\mathrm{SH}$ [16-20]. However, girls attending private schools in Polokwane showed a significantly high mean SH compared to that of boys in similar schools. This could be due

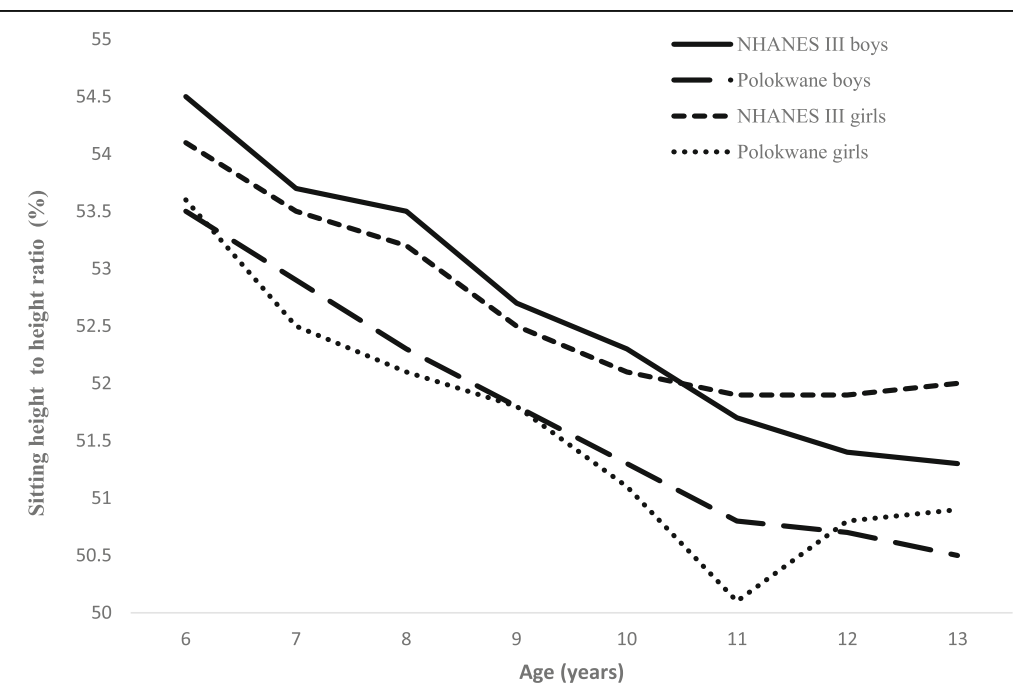

Fig. 4 The comparison of mean sitting height to height ratio between Polokwane and NHANES III children 
Table 2 Linear regression coefficients ( $\beta$ ), P-value and 95\% confidence intervals for the association between sitting height (SH), SH to height ratio $(\mathrm{SH} / \mathrm{H})$ and blood pressure among participants

\begin{tabular}{|c|c|c|c|c|c|c|c|c|}
\hline & \multicolumn{4}{|l|}{ Unadjusted } & \multicolumn{4}{|c|}{ Adjusted for age, gender and BMI } \\
\hline & Coefficient $(\beta)$ & $95 \% \mathrm{Cl}$ & & $P$-value & Coefficient ( $\beta$ ) & $95 \% \mathrm{Cl}$ & & $P$-value \\
\hline \multicolumn{9}{|l|}{$\mathrm{SBP}(\mathrm{mmHg})$} \\
\hline Height $(\mathrm{cm})$ & 0.540 & 0.221 & 0.387 & $<0.001$ & 0.304 & 0.221 & 0.387 & $<0.001$ \\
\hline $\mathrm{SH}(\mathrm{cm})$ & 1.318 & 1.217 & 1.418 & $<0.001$ & 0.691 & 0.509 & 0.872 & $<0.001$ \\
\hline $\mathrm{SH} / \mathrm{H}$ & -142.147 & -177.302 & -106.991 & $<0.001$ & -16.336 & -51.482 & 18.810 & $<0.362$ \\
\hline \multicolumn{9}{|l|}{$\mathrm{DBP}(\mathrm{mmHg})$} \\
\hline Height (cm) & 0.254 & 0.217 & 0.291 & $<0.001$ & 0.139 & 0.069 & 0.216 & $<0.001$ \\
\hline $\mathrm{SH}(\mathrm{cm})$ & 0.641 & 0.555 & 0.727 & $<0.001$ & 0.304 & 0.148 & 0.460 & $<0.001$ \\
\hline $\mathrm{SH} / \mathrm{H}$ & -53.111 & -80.461 & -25.760 & $<0.001$ & -9.876 & -39.692 & 19.940 & 0.516 \\
\hline
\end{tabular}

$\mathrm{Cl}$ confidence interval, SBP systolic blood pressure, $D B P$ diastolic blood pressure, $B M I$ body mass index

to the fast growth rate of girls compared with that of boys between 10 and 13 years of age as reported by Alan et al. [21]. Furthermore, an increase in mean $\mathrm{SH}$ and decreasing in mean $\mathrm{SH} / \mathrm{H}$ of NHANES III girls and boys with an increase in age was observed. However, $\mathrm{SH}$ and $\mathrm{SH} / \mathrm{H}$ values of NHANES III boys and girls were higher compared to their counterparts, private school attending boys and girls in Polokwane (Fig. 3-4). Indicating that in the pre-pubertal years, growth occurred more in the lower limbs than in the trunk in private school children as compared to NHANES III children. Moreover, this may be due to that private school attending children are/were from middle and upper socio-economic backgrounds in South Africa [22] while the NHANES III children were from developed countries.

Current results showed that $\mathrm{SH}$ is positively associated with SBP and DBP for both unadjusted and adjusted for age, gender and BMI among Polokwane private school attending children. Similar findings were reported among Chinese [9], Brazilian [8] and rural South African [10] children and adolescents. The possible explanation for these findings could be that BP at the heart level must surpass the hydrostatic pressure induced by vertical distance between the heart and the head, to ensure an adequate perfusion of a child's brain [23].

Based on a large sample in this study, the recognition of a significant association between components of height and BP in children and adolescents was examined for the first time in Polokwane private schools, South Africa. Components of height are simple, make use of inexpensive tools which can be used as an indicator of high BP among children [10, 23]. Furthermore, BP and components of height are more advantageous, due to their applicability and they are easily understood by the literate and illiterate population, particularly in areas of South Africa.

This study did not consider detailed information such as socio-economic and nutritional status of the children's families, dietary intake, physical activity and family history of hypertension. The BP and anthropometric measurements were taken directly; hence, recall or estimation bias will not prevail in our study. In addition, we measured BP during early childhood, signifying that early monitoring should commence from children's early days in order to identify and screen individuals that show vulnerability to associated risk factors [24].

\section{Conclusion}

In South African children, $\mathrm{SH}$ and $\mathrm{SH} / \mathrm{H}$ were low compared to the NHANES III children. There was significant association between SH with SBP and DBP, when unadjusted and adjusted for age, gender and BMI among the children attending private schools in Polokwane. In addition, $\mathrm{SH}$ can be used as a predictor of high BP among these children. Further interrogation of the relationship between components of height and BP in South African children is recommended overtime in order to shed more light on disease development and the factors thereof.

\section{Abbreviations}

BMI: Body mass index; BP: Blood pressure; DBP: Diastolic blood pressure; ISAK: International Society for the Advancement of Kinanthropometry; NHANES III: National Health and Nutrition Examination Survey III; SBP: Systolic blood pressure; SH: Sitting height; $\mathrm{SH} / \mathrm{H}$ : Sitting height to height ratio

\section{Acknowledgements \\ The authors are indebted to the Ellisras Longitudinal Study administrators, Mr. TT Makata, Ms. SP Seleka and Mr. W Makata for coding the data. Furthermore,} we thank our language editor, Sandra Duncan.

\section{Funding}

The financial support was received from Vrije University, Amsterdam, The Netherlands; University of Limpopo, South Africa; National Research Foundation.

\section{Availability of data and materials}

Due to confidentiality restrictions related to the ethics approval for this study, no identifying information about participants may be released. As recipients, the authors were allowed to publish analytic results from the data, but not the data itself, due to confidentiality conditions. 


\section{Authors' contributions}

NER participated in the analysis and interpretation of data, drafting the manuscript and its critical revision for important intellectual content. KDM participated in the study design, data collection, analysis and its interpretation, drafting the manuscript and its critical revision for important intellectual and administrative content. JM participated in the interpretation of data, drafting of the manuscript and its critical revision for important intellectual content. MSM participated in the analysis and interpretation of data, its critical revision for important intellectual content. All of the authors have read and approved the version of the manuscript.

\section{Ethics approval and consent to participate}

The Ethics Committee of the University of Limpopo granted ethical approval prior to the study and the parents or guardians were provided with written informed consent.

\section{Consent for publication}

Not applicable.

\section{Competing interests}

The authors declare that they have no competing interests.

\section{Publisher's Note}

Springer Nature remains neutral with regard to jurisdictional claims in published maps and institutional affiliations.

\section{Received: 5 April 2017 Accepted: 6 December 2017}

\section{Published online: 04 January 2018}

\section{References}

1. World Health Organisation. Obesity: preventing and managing the global epidemic. Report of a WHO consultation, Geneva, 3-5 Jun 1997. Geneva: WHO, 1998.

2. Pelletier $\mathrm{DL}$, Frongillo EA. Changes in child survival are strongly associated with changes in malnutrition in developing countries. J Nutr. 2003;133:107-19.

3. Sarganas G, Neuhauser HK. The persisting gender gap in hypertension management and control in Germany: 1998 and 2008-2011. Hypertens Res. 2016;28 doi: 10.1038

4. World Health Organization.Preventing chronic diseases: A Vital Investment: WHO Global Report. 2005.

5. Zhang Y, Zhao J, Chu Z, Wang L. The association between components of height and blood pressure among children and adolescents in Shandong, China. Int J Cardiol. 2015;182:18-9.

6. Regnault N, Kleinman KP, Rifas-Shiman SL, Lengenberg C, Lipshultz SE, Gillman MW. Componets of height and blood pressure in childhood. Int J Epidemol. 2014:43:149-59.

7. Lauer RM, Anderson AR, Beaglehole R, Burns TL. Factors related to tracking of blood pressure in children. U.S. National Center for Health Statistics health examination surveys cycles II and III. Hypertension. 1984:6:307-14.

8. Marcato DG, Sampaio JD, Alves ERB, de Jesus JSA, Fuly JTB, Giovaninni NPB. Sitting-height measure are related to body mass index and blood pressure in children. Arq Bras Endocrinol Metab. 2014;58:802-6.

9. Dong B, Wan Z, Ma J. Leg to trunk ratio and the risk of hypertension in children and adolescents: a population-based study. J Public Health. 2016; 203 doi: 10.1093

10. Ramoshaba N, Monyeki K, Hay L. Components of height and blood pressure among Ellisras rural children: Ellisras longitudinal study. Int J Environ Res Public Health. 2016;13 https://doi.org/10.3390/ijerph13090856.

11. Ledwaba KR, Nkalanga F, Monyeki KD, van Staden M. The relationship between mid-upper arm circumference and blood pressure of private school children aged 6-13 years, in Polokwane, Limpopo province, South Africa. Ann Pediatr Child Health. 2014;2:1026.

12. Norton K, Olds T. Anthropometrica. Sydney: University of New South Wales Press; 1996.

13. National High Blood Pressure Education Program Working Group on High Blood Pressure in Children and Adolescents. The fourth report on the diagnosis, evaluation, and treatment of high blood pressure in children and adolescents. Pediatrics. 2004;114:555-76.
14. National High Blood Pressure Education Program working group on hypertension control in children and adolescents. Update on the 1987 task force report on high blood pressure in children and adolescents: a working group report from the National High Blood Pressure Education Program. Pediatrics. 1996;98:649-58.

15. Frisancho AR Athropometric standards for the assessment of growth and nutritional status. Ann Arbor: the University of Michigan Press; 1990.

16. Fredriks AM, van Buuren S, Van Heel WJ, Dijkman-Neerincx RH, VerlooveVanhorick SP, Wit JM. Nationwide age references for sitting height, leg length, and sitting height/height ratio, and their diagnostic value for disproportionate growth disorders. Arch Dis Child. 2005;90:807-12.

17. Gerver WJ, De Bruin R. Relationship between height, sitting height and subischial leg length in Dutch children: presentation of normal values. Acta Paediatr. 1995;84:532-5.

18. Bogin B, Smith P, Orden AB, Varela Silva MI, Loucky J. Rapid change in height and body proportions of Maya American children. Am J Hum Biol. 2002;14:753-61.

19. Dangour AD, Schilg S, Hulse JA, Cole TJ. Sitting height and subischial leg length centile curves for boys and girls from Southeast England. Ann Hum Biol. 2002;29:290-305.

20. Tanner JM. Principles of growth standards. Acta Paediatr Scand. 1990;79:963-7.

21. Alan DR, Pamela AC, James NR. Growth and pubertal development in children and adolescents: effects of diet and physical activity. Am J Clin Nutr. 2000;72(suppl):521S-8S

22. Amiena B, Wynand L, Ravinder R. The impact of socio-economic factors on the performance of selected high school learners in the western Cape Province, South Africa. J Hum Ecol. 2014;45:183-96.

23. Regnault N, Kleinman KP, Rifas-Shiman SL, Lengenberg C, Lipshultz SE, Gillman MW. Components of height and blood pressure in childhood. Int J Epidemol. 2014:43:149-59.

24. Monyeki KD, Kemper HCG. The risk factors for elevated blood pressure and how to address cardiovascular risk factors: a review in pediatric populations. J Hum Hypertens. 2008;22:450-9.

\section{Submit your next manuscript to BioMed Central and we will help you at every step:}

- We accept pre-submission inquiries

- Our selector tool helps you to find the most relevant journal

- We provide round the clock customer support

- Convenient online submission

- Thorough peer review

- Inclusion in PubMed and all major indexing services

- Maximum visibility for your research

Submit your manuscript at www.biomedcentral.com/submit
Biomed Central 